\title{
Correction to: Organized simultaneous displays facilitate learning of complex natural science categories
}

\author{
Brian J. Meagher ${ }^{1} \cdot$ Paulo F. Carvalho ${ }^{2} \cdot$ Robert L. Goldstone $^{1} \cdot$ Robert M. Nosofsky $^{1}$
}

Published online: 11 July 2018

(C) Psychonomic Society, Inc. 2018

\section{Correction to: Psychon Bull Rev \\ https://oi.org/10.3758/s13423-017-1251-6}

The affiliation for Dr. Paulo F. Carvalho is listed incorrectly in this paper. The correct affiliation is Carnegie Mellon University, Pittsburgh, PA, USA

The online version of the original article can be found at https://doi.org/ $10.3758 / \mathrm{s} 13423-017-1251-6$

$\triangle$ Robert M. Nosofsky nosofsky@indiana.edu

1 Department of Psychological and Brain Sciences, Indiana University, 1101 East Tenth Street, Bloomington, IN 47405, USA

2 Carnegie Mellon University, Pittsburgh, PA, USA 